\title{
Damage to extreme-ultraviolet Sc/Si multilayer mirrors exposed to intense 46.9-nm laser pulses
}

\author{
M. Grisham, G. Vaschenko, C. S. Menoni, and J. J. Rocca \\ National Science Foundation Engineering Research Center for Extreme Ultraviolet Science and Technology, and \\ Department of Electrical and Computer Engineering, Colorado State University, Fort Collins, Colorado 80523 \\ Yu. P. Pershyn, E. N. Zubarev, D. L. Voronov, V. A. Sevryukova, and V. V. Kondratenko \\ Department of Metal and Semiconductor Physics, National Technical University "Kharkov Polytechnical Institute," Kharkov, Ukraine
}

\author{
A. V. Vinogradov and I. A. Artioukov
}

P. N. Lebedev Physical Institute, Moscow 117942, Russia

Received August 21, 2003

\begin{abstract}
The damage threshold and damage mechanism of extreme-ultraviolet $\mathrm{Sc} / \mathrm{Si}$ multilayer mirror coatings are investigated with focused nanosecond pulses at 46.9-nm radiation from a compact capillary-discharge laser. Damage threshold fluences of $\sim 0.08 \mathrm{~J} / \mathrm{cm}^{2}$ are measured for coatings deposited on both borosilicate glass and Si substrates. The use of scanning and transmission electron microscopy and small-angle x-ray diffraction techniques reveals the thermal nature of the damage mechanism. The results are relevant to the use of newly developed high-flux extreme-ultraviolet sources in applications. (C) 2004 Optical Society of America

OCIS codes: $340.7470,230.4170,140.7240$.
\end{abstract}

High-reflectivity mirrors for the extreme-ultraviolet (EUV) range with a high damage threshold are key elements for numerous applications of the rapidly advancing high-power coherent EUV sources that include new tabletop sources ${ }^{1,2}$ and free-electron lasers..$^{3,4}$ Significant progress has been made in developing high-reflectivity $\mathrm{Sc} / \mathrm{Si}$ mirrors for the 35-50-nm range, with measured reflectance values as high as $54 \%{ }^{5}$ However, the damage to these mirrors when exposed to high peak powers of EUV light has not been studied to our knowledge. This problem is now of particular relevance because the peak power and fluence of EUV sources have recently increased significantly (for example, the radiation fluence at the exit of a capillary-discharge Ne-like Ar laser operating at $46.9 \mathrm{~nm}$ can exceed $1 \mathrm{~J} / \mathrm{cm}^{2}$ ) and is soon expected to achieve unprecedented values with the commissioning of EUV free-electron lasers. ${ }^{2-4}$ In this Letter we report results of the study of the optical damage mechanisms and the damage threshold for Sc/Si EUV mirrors exposed to high-power EUV laser radiation. The study was conducted by focusing the output of a tabletop capillary-discharge Ne-like Ar laser emitting nanosecond duration pulses at a wavelength of $46.9 \mathrm{~nm}$. The resulting damage to the multilayer coatings exposed to the EUV beam was analyzed with scanning electron microscopy (SEM), transmission electron microscopy (TEM), and small-angle x-ray diffraction $(\lambda=0.154 \mathrm{~nm})$ techniques. Our results show that multilayer coatings on $\mathrm{Si}$ and borosilicate glass have similar damage threshold values of $\sim 0.08 \mathrm{~J} / \mathrm{cm}^{2}$, compared with the $0.7 \mathrm{~J} / \mathrm{cm}^{2}$ found necessary to damage a bare $\mathrm{Si}$ substrate. These values are similar to the thresholds found in $\mathrm{Mo} / \mathrm{Si}$, $\mathrm{W} / \mathrm{C}$, and $\mathrm{W} / \mathrm{Si}$ coatings measured at much shorter wavelengths. ${ }^{6,7}$
The Sc/Si multilayers were deposited by dc magnetron sputtering at $3 \mathrm{mTorr}$ of Ar pressure on superpolished borosilicate glass (surface roughness of $\sigma \sim$ $0.4 \mathrm{~nm})$ and on $\mathrm{Si}$ wafers $(\sigma \sim 0.6 \mathrm{~nm})$. The multilayers on borosilicate glass consisted of ten periods of $\mathrm{Sc} / \mathrm{Si}$ layers, each with a thickness of $\sim 26.7 \mathrm{~nm}$ and a ratio of layer thickness of $\mathrm{H}(\mathrm{Sc}) / \mathrm{H}(\mathrm{Si}) \sim 0.7$. A top 5-nm-thick Si protection layer capped the multilayers. The multilayer coatings deposited on Si consisted of 33 periods of $\mathrm{Sc} / \mathrm{Si}$ pairs with the same parameters as those deposited on borosilicate glass. In these structures the crystalline Sc layers were always separated from the amorphous Si layers by $\sim 3 \mathrm{~nm}$ of amorphous $\mathrm{ScSi}$ interface layers formed by interdiffusion. ${ }^{8}$

The experimental setup used to irradiate the samples was described in Ref. 9. The laser emission was focused onto the target surface with a spherical $R=10 \mathrm{~cm} \mathrm{Sc} / \mathrm{Si}$ multilayer-coated mirror that was $2.5 \mathrm{~cm}$ in diameter and positioned at normal incidence. The reflectivity of this particular mirror was measured to be $\sim 30 \%$ at $46.9 \mathrm{~nm}$. The capillarydischarge Ne-like Ar laser used as a source of EUV radiation was configured to produce pulses with an energy of $\sim 0.13 \mathrm{~mJ}$ and a duration of $\sim 1.2 \mathrm{~ns}$ FWHM. $^{1}$ The far-field laser beam profile had an annular shape with a peak-to-peak divergence of $\sim 4.6 \mathrm{mrad}$. The $\mathrm{Sc} / \mathrm{Si}$ multilayer samples were cut to a $3 \mathrm{~mm} \times 5 \mathrm{~mm}$ size and mounted on a $1.6-\mathrm{mm}$-thick brass strip holder positioned at $1.45 \mathrm{~m}$ from the exit of the laser. The sample and the holder intercept a small fraction of the laser beam, ${ }^{9}$ which in that plane has a diameter of $\sim 13 \mathrm{~mm}$. Motorized translation stages were used to allow for the motion of the sample along an axis that forms an angle of $\sim 50^{\circ}$ with respect to the laser beam and for its accurate positioning in the horizontal and vertical directions. The displacement 
of the samples along this axis allowed us to vary the distance between the sample and the focal spot $(\sim 5 \mu \mathrm{m}$ in diameter) to select EUV radiation fluences from $\sim 0.01$ to $>10 \mathrm{~J} / \mathrm{cm}^{2}$ while simultaneously changing the target area irradiated by the beam after each shot. In some samples individual spots were irradiated by single laser shots, whereas in others a large number of shots were used to uniformly irradiate $2 \mathrm{~mm} \times 2 \mathrm{~mm}$ areas with a fixed EUV fluence to allow for x-ray diffraction studies of the damaged films. These large-area exposures were accomplished by scanning the sample in the horizontal and the vertical directions in front of the laser beam to overlap each individual irradiated zone while firing the laser at a repetition rate of $1 \mathrm{~Hz}$. This experiment constitutes, to our knowledge, the first demonstration of a relatively large-area material's modification with a high-power EUV laser beam.

Figure 1 shows typical SEM images of damaged areas in coatings deposited on a $\mathrm{Si}$ wafer resulting from average EUV fluences of $0.13,1.5$, and $2.8 \mathrm{~J} / \mathrm{cm}^{2}$. At $0.13 \mathrm{~J} / \mathrm{cm}^{2}$ [Fig. 1(a)] we observe large areas with apparent discoloration. These areas are most likely produced by heat-triggered interdiffusion in the upper layers of the coatings. This surface modification, which already appears at fluences of $\sim 0.08 \mathrm{~J} / \mathrm{cm}^{2}$, establishes the damage threshold for the $\mathrm{Sc} / \mathrm{Si}$ multilayers defined in this work. In comparison, the onset of damage in bare $\mathrm{Si}$ substrates measured in this work occurs at a significantly larger irradiation fluence of $0.7 \mathrm{~J} / \mathrm{cm}^{2}$. The areas with larger local fluences [Fig. 1(a)] are molten and covered with cracks resulting from significant mechanical tensile stress generated by thermal expansion and the following cooling down process. ${ }^{10}$ At larger fluences $\left(1.5 \mathrm{~J} / \mathrm{cm}^{2}\right)$ some of the molten material is displaced toward the periphery, forming a crown [Fig. 1(b)]. Also, a substantial concentration of cracks and micrometer-sized pits resulting from boiling are observed. At even larger fluences of $\sim 3 \mathrm{~J} / \mathrm{cm}^{2}$ the coating is fully evaporated from the center of the irradiated spot and the $\mathrm{Si}$ substrate is also damaged [Fig. 1(c)]. Electron microanalysis data reveal that $\mathrm{Sc}$ is absent in the center part of the dark spot shown in Fig. 1(c).

Small-angle x-ray diffraction analysis of the samples with $2 \mathrm{~mm} \times 2 \mathrm{~mm}$ area irradiated with $\geq 0.1 \mathrm{~J} / \mathrm{cm}^{2}$ emission fluence shows a noticeable drop in the intensity of the diffraction peaks with respect to the unexposed areas. Thus the sample irradiated with a fluence of $\sim 0.13 \mathrm{~J} / \mathrm{cm}^{2}$ loses $20-30 \%$ in diffraction intensity, whereas that in which the fluence was $\sim 0.21 \mathrm{~J} / \mathrm{cm}^{2}$ (Fig. 2) loses $75-85 \%$. However, the diffraction peak's position remains approximately the same, indicating that the coating is only partially destroyed. This evidence suggests that, whereas at these fluences the top layers of the coating are molten, the layers adjacent to the substrate remained unchanged. This interpretation of the x-ray diffraction data was confirmed by cross-sectional TEM imaging of the sample exposed at $0.21 \mathrm{~J} / \mathrm{cm}^{2}$. The TEM image of Fig. 3(a) shows that the top $700 \mathrm{~nm}$ of the coating are molten, whereas $\sim 180 \mathrm{~nm}$ (seven periods) adjacent to the substrate are not destroyed. The top molten layer constitutes an alloy of $\mathrm{Sc}_{3} \mathrm{Si}_{5}$ and crystal $\mathrm{Si}$ as determined from electron diffraction data. Analysis of the surviving multilayer coating beneath the molten layer indicates that changes in layer thickness have occurred within a distance of less than two periods

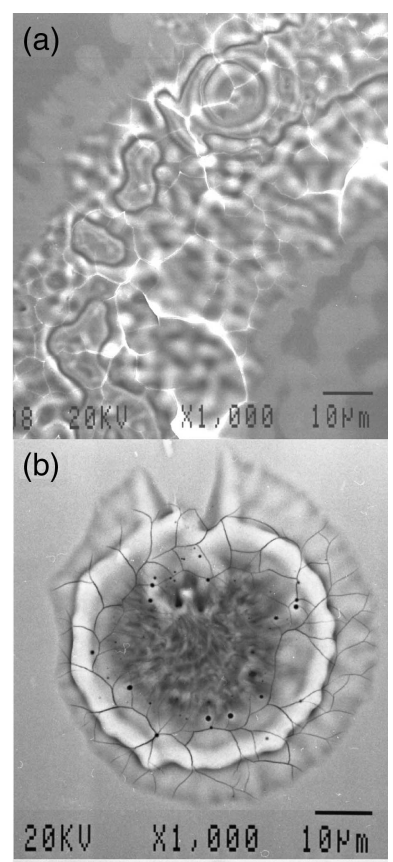

(c)

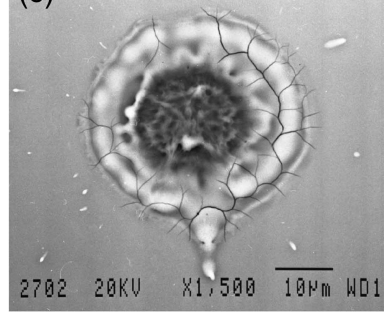

Fig. 1. SEM micrographs of the damaged areas of the $\mathrm{Sc} / \mathrm{Si}$ coatings exposed to EUV laser beam fluences of (a) $0.13 \mathrm{~J} / \mathrm{cm}^{2}$, (b) $1.5 \mathrm{~J} / \mathrm{cm}^{2}$, and (c) $2.8 \mathrm{~J} / \mathrm{cm}^{2}$. Only a segment of the entire damaged area is shown in (a).

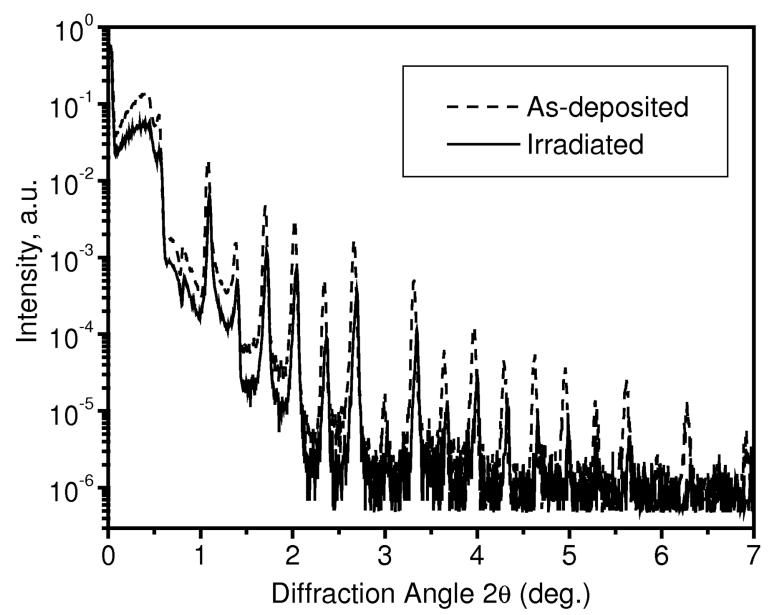

Fig. 2. Small-angle x-ray diffraction patterns in the asdeposited and EUV-irradiated coatings. Laser fluence, $0.21 \mathrm{~J} / \mathrm{cm}^{2}$. 


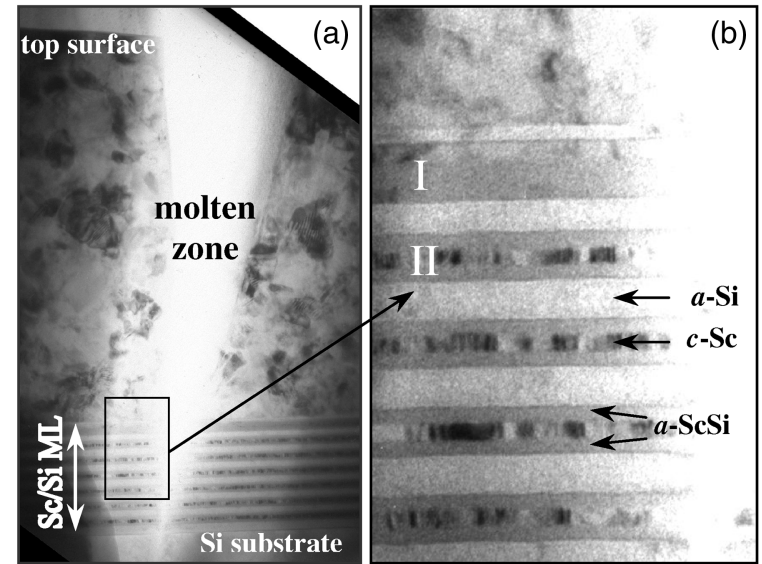

Fig. 3. Cross-sectional TEM image of (a) the molten zone and (b) survived layers (magnified) of a sample irradiated with $0.21 \mathrm{~J} / \mathrm{cm}^{2}$ pulses of $46.9-\mathrm{nm}$ radiation.

from the molten region (Fig. 3); thus the heat-affected zone did not exceed $\sim 50 \mathrm{~nm}$.

Comparison of the layer structure in the heataffected zone with that of isothermally annealed samples indicates that the various stages of structural and phase transformations observed within a few periods of the coating under laser irradiation are the same as in samples annealed at different temperatures. Both structural and phase transformations in $\mathrm{Si} / \mathrm{Sc}$ multilayers at temperatures as high as $970{ }^{\circ} \mathrm{C}$ have been previously studied in detail. ${ }^{11}$ The changes taking place in the Sc-containing layer nearest to the molten region [indicated by I in Fig. 3(b)] correspond to a stage of formation and crystallization of $\mathrm{Sc}_{3} \mathrm{Si}_{5}$ silicide that have been observed in isothermally annealed coatings at $430^{\circ} \mathrm{C}$ after $1 \mathrm{~h}$. In the next Sc-containing layer [indicated by II in Fig. 3(b)], only minor expansion of the $\mathrm{ScSi}$ silicide interface layers is observed, which is a result of solid-state amorphization. Similar effects have been observed at annealing temperatures of less than $200{ }^{\circ} \mathrm{C} .{ }^{11}$ The insertion of antidiffusion barriers at $\mathrm{Sc}-\mathrm{Si}$ interfaces might help to increase the damage threshold of these multilayers, as suggested by the increased heat resistance observed in the isothermally heated structures with such barriers. ${ }^{11}$

In summary, we have investigated the damage threshold and damage mechanisms in $\mathrm{Sc} / \mathrm{Si}$ multilayer EUV mirrors exposed to intense $46.9-\mathrm{nm}$ nanosecond pulses. The study reveals the thermal character of the changes in the mirror coatings underlying the irradiation damage. A damage threshold of $\sim 0.08 \mathrm{~J} / \mathrm{cm}^{2}$ was measured in the multilayer mirror coatings deposited on $\mathrm{Si}$ or borosilicate glass substrates, compared with a measured value of $0.7 \mathrm{~J} / \mathrm{cm}^{2}$ for bare Si substrates. These results are relevant to the use of these mirrors in combination with newly developed high-power EUV sources and provide a benchmark for their further improvement.

This work was supported by the U.S. Department of Energy's Chemical Sciences, Geosciences and Biosciences Division of the Office of Basic Energy Sciences and in part by the Engineering Research Centers Program of the National Science Foundation under award EEC-0310717. The Colorado State University researchers also gratefully acknowledge the support of the W. M. Keck Foundation. The authors are indebted to Yu. S. Kasjanov for helpful discussions. G. Vaschenko's e-mail address is vaschen@ engr.colostate.edu.

\section{References}

1. B. R. Benware, C. D. Macchietto, C. H. Moreno, and J. J. Rocca, Phys. Rev. Lett. 81, 5804 (1998).

2. C. D. Macchietto, B. R. Benware, and J. J. Rocca, Opt. Lett. 24, 1115 (1999).

3. M. V. Yurkov, At. Energy 94, 108 (2003).

4. L. H. Yu, L. DiMauro, A. Doyuran, W. S. Graves, E. D. Johnson, R. Heese, S. Krinsky, H. Loos, J. B. Murphy, G. Rakowsky, J. Rose, T. Shaftan, B. Sheehy, J. Skaritka, X. J. Wang, and Z. Wu, Phys. Rev. Lett. 91, 074801 (2003).

5. Yu. A. Uspenskii, V. E. Levashov, A. V. Vinogradov, A. I. Fedorenko, V. V. Kondratenko, Yu. P. Pershin, E. N. Zubarev, and V. Yu. Fedotov, Opt. Lett. 23, 771 (1998).

6. B. J. MacGowan, S. Mrowka, T. W. Barbee, Jr., L. B. DaSilva, D. C. Eder, J. A. Koch, L. S. Pan, J. A. Turner, J. H. Underwood, and P. E. Young, J. X-Ray Sci. Technol. 3, 231 (1992).

7. F. Leguern, J.-M. André, J.-P. Lebreton, J.-L. Dutrannoy, J.-P. Chauvineau, K. Krastev, J.-L. Larcade, D. Friart, C. Nazet, and R. Barchewitz, J. X-Ray Sci. Technol. 7, 271 (1997).

8. A. I. Fedorenko, Yu. P. Pershin, O. V. Poltseva, A. G. Ponomarenko, V. S. Sevryukova, D. L. Voronov, and E. N. Zubarev, J. X-Ray Sci. Technol. 9, 35 (2001).

9. B. R. Benware, A. Ozols, J. J. Rocca, I. A. Artioukov, V. V. Kondratenko, and A. V. Vinogradov, Opt. Lett. 24, 1714 (1999).

10. S. K. Lee, W. S. Chang, and S. J. Na, J. Appl. Phys. 86, 4282 (1999).

11. D. L. Voronov, E. N. Zubarev, V. V. Kondratenko, A. V. Penkov, Y. P. Pershin, A. G. Ponomarenko, I. A. Artioukov, A. V. Vinogradov, Y. A. Uspenskii, and J. F. Seely, AIP Conf. Proc. 641, 575 (2002). 